\title{
Analyzing The Level Of Harassment Within The University
}

\author{
Asma Manzoor \\ Women's Studies \\ University of Karachi \\ Muhammad Nadeemullah \\ Department of Social Work \\ University of Karachi \\ Syed Faisal Hashmi \\ Women's Studies \\ University of Karachi
}

\begin{abstract}
Over a three decades have passed since Hall and Sandler coined the term "chilly climate" citing sexual victimization as one of many factors that contribute to an inhospitable situation for women in academia ${ }^{1}$. The current study illustrates that sexual harassment remain pervasive in the University environment, profoundly and negatively affecting women students' lives.

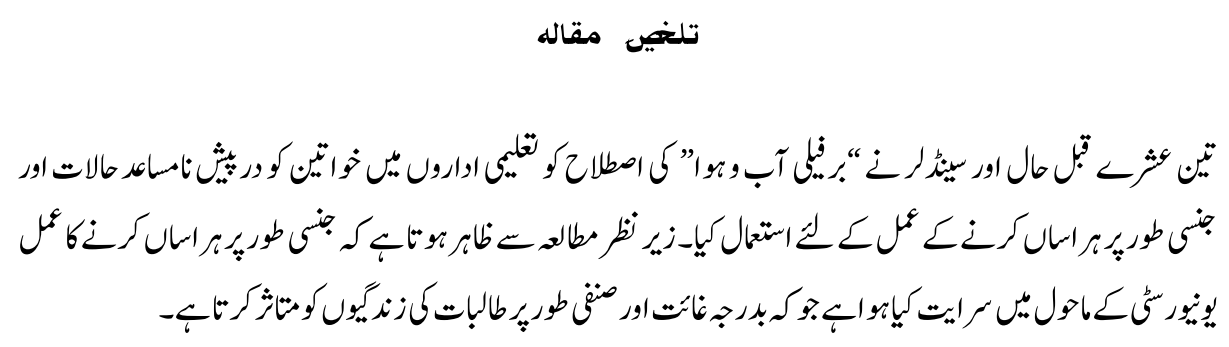

\section{Introduction}

Sexual harassment is any irritating behavior that feels offensive. Also includes unwelcome sexual advances, requests for sexual favors, and unwelcome verbal or physical conduct of a sexual nature that occur in public place or at workplace or on campus.

Harassment is a worldwide issue though it is faced by both men and women but mostly it is referred to female. It is basically a new term first used in sixties and before that no one knew how to name the offensive behavior they faced in the lives.

Academic scholars studying sexual harassment are often working at cross purposes with legal scholars; the traditions, methodologies, assumptions and conclusions of academic 
scholars are different from those used by legal scholars. Feminist scholars in particular argue that the legal system, being male dominated, does not understand or honor the perspectives of women who have been harassed.

It is now recognized by state as an offensive act and punishment is set to be given to the harasser. According to an ILO survey, among the industrialized countries only Australia, Canada, France, New Zealand, Spain, Sweden and the United States have specific laws regarding sexual harassment ${ }^{2}$. Other industrialized countries cover sexual harassment under laws on criminal law. Australia, Canada, Denmark, Ireland, New Zealand, Sweden, the United Kingdom, and the United States have equal employment opportunity laws as well. France is the only country that has passed a criminal law related to sexual harassment, although some criminal laws in other countries may apply to extreme cases of sexual harassment such as assault or indecent behavior ${ }^{3}$.

Researchers have found that women and men interpret sexualized behavior in the workplace differently. Women are much more likely than men to label a given situation as harassing. Men report that they would be flattered by sexual attention at work, while women report that they are annoyed by similar behavior. Scholars point out that the power dynamic between male bosses and female employees may account for such differential interpretations. Some scholars have theorized that since women are more likely to be subject to sexual violence, they are more sensitive to sexual behavior in the workplace.

One study presented women and men with a series of hypothetical scenarios and asked them whether or not they would label the behaviors as sexual harassment. In one scenario, a male supervisor invited a new female employee to lunch to discuss her work. He focused the conversation on her personal life. On another occasion, over drinks, he attempted to fondle her. Most of the women said that the sexual harassment began with the lunch, while most of the men thought it began later when he attempted to fondle her ${ }^{4}$.

Researchers are beginning to turn from studying sexual harassment as a problem between individuals to a problem of organizational climate. Harassment is more likely in an environment in which employees perceive that management does not take victims seriously or takes punitive measures against women who speak out, or where administrators inadequately enforce anti-sexual harassment policies against offenders. Factors like the status of women in the organization, the perception of women as an out group, and the general acceptance of nonprofessional behavior may contribute to prosexual harassment norms.

Pakistan too has particular laws to deal with sexual harassment and a mile stone has achieved when the State of Pakistan has passed a historic bill against sexual harassment 
"Protection Against Harassment of Women at Workplace Act 2010"

The sexual harassment in educational institutions is also very common. Researches revealed that in some cases students have left institutions with the fear of being harassed ${ }^{6}$. And it is a big issue to be dealt specially against sexual harassment in schools. In most cases the male students trying to show their supremacy over girls use different mechanism and acquire such behavior that is infuriating and annoying.

Some students, men and women, just don't want to hear classroom references to sex. But to suggest that comments about sex necessarily are more offensive to women than to men is stereotyping, in itself gender discrimination. It suggests that women ought to be treated as children--sheltered from the troubling talk of the grownup world. We once thought women ought to be sheltered from university life altogether, certainly from professional schools, because they were, as a class, better suited to home and family than to the rough and tumble of careers. Are we now saying that women, once admitted to the university, may not hear all that will be said there? While we work to free our students from sexual harassment, we must also guard against a return to the crippling gender-based protectionism of a time gone by, when someone else made all women's choices for them ${ }^{7}$.

Almost $35 \%$ of female college students experience sexual harassment on campus, according to a recent study by the Minnesota Public Research Interest Group. The group surveyed 873 students from private and public schools throughout Minnesota. They found behaviors such as pinching, cornering, verbal abuse and assault occurring on campus. Less than $20 \%$ of harassed women filed formal complaints with their schools ${ }^{8}$.

A study of sexual harassment and assault and their effects on 1,037 female undergraduate and graduate students at a large Midwestern university found that about $40 \%$ of undergraduate and graduate women experienced harassment in their first year at the university, as did $60 \%$ of undergraduate students and more than $70 \%$ of graduate students beyond the fourth year. Only about $20-25 \%$ of women students recognized and labeled sexually harassing behaviors when they experienced them. Of the $50 \%$ of women who faced harassment, about two thirds reported more than one or two incidents. Lesbians and bisexuals were more likely to report sexual harassment, with nearly two thirds reporting gender harassment. More than $10 \%$ of female undergrads reported being sexually assaulted while on campus ${ }^{9}$.

\section{Theories of Harassment}

\section{Patriarchy}

This perspective holds that the cultural structure of patriarchy ("Rule by the Fathers") is the root cause of sexual harassment. Within this social structure men have social, political, 
and economic power over women, who are defined by the system as sexual in nature ${ }^{10}$. In some traditional patriarchal cultures women are confined to the home as wives and mothers and female children are not formally educated. In other cultures such as our own, women are not confined to the home but stereotypes about appropriate male and female behavior assign women a subordinate sexualized identity even in the workplace.

\section{Sociobiology}

This perspective holds that men are biologically programmed to be sexual aggressors and that sexual behavior in the workplace is one aspect of that biological inheritance. At the center of this analysis is the assumption that sexual harassment is about sex. Proponents of this position may admit that some of the sexual behavior in the workplace is inappropriate, but they argue that it is unavoidable ${ }^{11}$.

\section{Culture}

This perspective holds that women and men are socialized into different culturesdifferent beliefs, values, and ways of communicating. Traditionally the workplace has been a male culture where men joke, compete with and tease one another, and talk about women in less than respectful ways. Women who want to enter this workplace cannot expect men to change their culture quickly; however, men must learn to get along with women in the workplace. Women have to learn to be tougher and men have to learn to behave more respectfully when women are around ${ }^{12}$.

\section{Discourse}

A discursive perspective holds that communication creates and shapes social reality. Language and our communicative practices embody assumptions about the nature of the world and the nature of truth that influence our opinions and behaviors. Everyday takenfor-granted communication activities reproduce and sustain oppressive conditions such as sexual harassment. Not only actions but also feelings and emotions are defined and taught, so that people who harass and people who are harassed come to feel those behaviors are "normal"13.

\section{Literature Review}

A research report revealed that $91.7 \%$ of the women hosteller respondents reported having faced harassment on the campus in Delhi University. $45 \%$ of women stated that sexual harassment on Delhi campus roads has affected their personal or academic development in one way or another. Women said that even when they have gone ahead to complain to the police nothing has been done about it. According to the report $20.2 \%$ women hostellers said that they have faced sexual harassment from policemen, this includes staring, winking and lewd comments ${ }^{14}$. 
During the 1999 fall semester, Pennsylvania State University 5-25 students complained of computer-based harassment and misuse per day. Students and faculty report being "stalked" over e-mail, receiving death threats, or even having their personal computers "hijacked" with disturbing and gruesome images automatically popping up on their screens.

The Association of American University Women (AAUW) found that about 1 in 5 girls reported sexual violence, rape, pressure to have sex, or harassment as a major issue or struggle. Previous studies have shown that about 80 percent of girls and 60 percent of boys have experienced unwanted sexual attention ${ }^{15}$.

Another survey conducted by the American Association of University Women (AAUW) to analyze the Sexual Harassment Statistics in Education on 1632 students aged 8-11 revealed:

- $85 \%$ of girls have been sexually harassed

- $76 \%$ of boys have been sexually harassed

- $31 \%$ of girls experienced harassment "often"

- $18 \%$ of boys experienced harassment "often"

- $13 \%$ of girls reported being "forced to do something sexual at school other than kissing"

- $9 \%$ of boys reported being "forced to do something sexual at school other than kissing"

- Girls were five times more likely to find the incidents disturbing and three times more likely to feel the harassment had affected their grades.

- $25 \%$ of girls were harassed by school employees

- $10 \%$ of boys were harassed by school employees ${ }^{16}$

A survey conducted by the American Psychological Association on female graduate students revealed:

- $12.7 \%$ have experienced sexual harassment

- $21 \%$ have avoided classes for fear of being sexually harassed

- $11 \%$ have tried to report an incident of sexual harassment

- $3 \%$ have dropped a course because of sexual harassment

A survey conducted on Minnesota high school students (reported by Susan Strauss, Sexual Harassment and Teens) revealed:

- $80 \%$ were aware of sexual harassment occurring in their school

- $75 \%$ were aware of sexual harassment between students

- $50 \%$ were aware of sexual harassment of students by faculty ${ }^{17}$ 


\section{Objectives}

- Analyzing the level of harassment faced by university students

- To analyze how harassment is depicted by students

- To see the impact of harassment on the educational environment

- Analyzing the kinds of harassments students mostly face

- Evaluating the harassment faced by students at public place

- To analyze the level of harassment in educational institution

\section{Methodology}

Qualitative research was conducted through questionnaire method. The total sample size was 80 students that comprised of 40 male and 40 female students. Departments from both science and arts were taken, 5 departments from arts and 5 from science faculty were selected and 8 students were taken from each department. 1 male and 1 female student was taken from $1^{\text {st }}$ year, $2^{\text {nd }}$ year, 3 rd year and final year from each dept. the data collection team comprised of 10 members and 8 questionnaires were distributed among each member. Harassment is not a subject that is used in normal routine and some people hesitate to share such incidences. Some of the students refused to talk of harassment and others didn't give proper information.

\section{Knowledge of Harassment}

Among the total 80 students, $87.5 \%$ knew what harassment is while the remaining $12.5 \%$ said they don't know about it, though when they were asked if they had ever commented on someone's dressing or physique, they said yes but they said that is not something offensive because that is for enjoyment.

\section{Table No 1}

\begin{tabular}{|l|c|c|}
\hline Understanding of Harassment \\
\hline Unwategories & Frequency & Percentage \\
\hline Unwanted comments & 17 & $21.25 \%$ \\
\hline Fun/ Enjoyment & 7 & $8.75 \%$ \\
\hline Threatening behavior & 3 & $3.7 \%$ \\
\hline Pressurize/ Dominate & 17 & $21 \%$ \\
\hline Unpleasant behavior & 6 & $7.5 \%$ \\
\hline Sexual Desire & 6 & $7.5 \%$ \\
\hline Mental/Physical torture & 3 & $3.7 \%$ \\
\hline Not sure & 7 & $8.75 \%$ \\
\hline No comments & 4 & $5 \%$ \\
\hline Total & 10 & $12.5 \%$ \\
\hline
\end{tabular}


While asking about the understanding of harassment $21 \%$ said unwanted comments as it was what they had experienced the most. A similar number of students referred to a threatening behavior. Some of them nearly $8.7 \%$ associated harassment with mental/physical torture and unwanted touching. A few of them took it only for fun and enjoyment which is $3.7 \%$. Some said it is to pressurize people by showing their dominance specially by men to show their supremacy. An equal number of students said harassment is an unpleasant behavior. A few of them also referred to harassment as sexual desire as it is mostly towards the opposite sex. 5\% said that they understand what harassment is but cannot explain it. $12.5 \%$ of the students refused to give any comments on.

While asking about the level of harassment a prominent number of students which is $21 \%$ said that they were never harassed the reason might be because they didn't understand what harassment stands for and have might taken harassment for severe cases only. 35\% said they are rarely harassed and $11.25 \%$ said that they are harassed very often. The occurrence of harassment can be clearly seen here.

\section{Way of being Harassed}

Most of the respondents' complaint of verbal harassment which is $47.5 \%$ usually comprised of comments. $21.5 \%$ said that Phone is also used as a medium for harassment, where as $20 \%$ also complaint of being harassed by unwanted touching mostly at bus stops and in public buses by the conductor and sometimes by the driver also and 3.7\% complaints of chasing and whistling.

\section{Place of Harassment}

The table very clearly shows the level of harassment at different places. Mostly $37.5 \%$ of the students faced harassment at the university, $16.2 \%$ said that they were harassed at marketplace, and $17.5 \%$ of the students complained of being harassed at bus stops. It was told by some of the students that they faced unpleasant behavior at roads while going home or elsewhere.

\section{Response to the Harasser}

Table clearly shows that $21.2 \%$ of the harassed took no action and just ignored where as $8.7 \%$ smiled and taking it for fun. But most of them were angry though they took no verbal response. Some of them when asked told that taking action only encourages the harasser so one should keep silence. Only $10 \%$ of the students gave verbal response in order to 'revenge' as told. 


\section{Reaction of Harasser to the Response}

In one case where verbal response was given by the harassed, the accused was annoyed. But mostly the harasser enjoyed particularly when the victim showed their anger. Most of them replied that giving response to the harasser only encouraged him/her.

\section{Number of Harassed who Reported the Incident}

Only $12.5 \%$ students reported the incidence of harassment, that too, to the family or friend but never reported in a police station. The majority of $77.5 \%$ students didn't feel it was a big issue to be reported. Some of them said because it's a part of everyday life and no one has enough time to go after such 'minor' problems.

\section{Table No 2}

\section{Result of Reporting Harassment}

\begin{tabular}{|l|c|c|}
\hline (a) With the complaint & Frequency & Percentage \\
\hline No action would be taken & 57 & $71.2 \%$ \\
\hline It would take long time & 12 & $15 \%$ \\
\hline It would be dealt quickly & 11 & $13.7 \%$ \\
\hline Total & $\mathbf{8 0}$ & $\mathbf{1 0 0 \%}$ \\
\hline
\end{tabular}

\begin{tabular}{|l|c|c|}
\hline (b) With the harassment & Frequency & Percentage \\
\hline It would stop & 9 & $11.2 \%$ \\
\hline It would decrease & 26 & $32.5 \%$ \\
\hline It would not change & 22 & $27.5 \%$ \\
\hline It would increase & 23 & $28.7 \%$ \\
\hline Total & $\mathbf{8 0}$ & $\mathbf{1 0 0 \%}$ \\
\hline (c)With the harasser & Frequency & Percentage \\
\hline He/she would change positively & 10 & $10 \%$ \\
\hline $\begin{array}{l}\text { He/she would receive justified } \\
\text { punishment }\end{array}$ & 18 & $12.5 \%$ \\
\hline $\begin{array}{l}\text { He/she would receive little } \\
\text { punishment }\end{array}$ & 44 & $22.5 \%$ \\
\hline $\begin{array}{l}\text { He/she would receive no punishment } \\
\text { at all }\end{array}$ & $\mathbf{8 0}$ & $\mathbf{1 0 0 \%}$ \\
\hline Total & & \\
\hline
\end{tabular}

On asking what would have been the consequences if the harassment was reported, the majority of the $71.2 \%$ students said that no action would have been taken against the harasser and $32.5 \%$ replied that harassment would not changed but rather would increase by the so called security providers. Most of them assumed that even on reporting no 
punishment would be given to the accused or in some cases would receive only little punishment.

Table No 3

Whether the Harasser should be Responded or not

\begin{tabular}{|l|c|c|}
\hline Response be given & Frequency & Percentage \\
\hline Yes & 42 & $52.5 \%$ \\
\hline No & 31 & $38.7 \%$ \\
\hline No response & 7 & $8.75 \%$ \\
\hline Total & $\mathbf{8 0}$ & $\mathbf{1 0 0 \%}$ \\
\hline
\end{tabular}

(a)Why response should be given

\begin{tabular}{|l|c|c|}
\hline Categories & Frequency & Percentage \\
\hline To discourage harasser & 28 & $66.6 \%$ \\
\hline Control oneself & 3 & $7.1 \%$ \\
\hline Because of the attitude of harasser & 3 & $7.1 \%$ \\
\hline To feel comfortable & 2 & $4.7 \%$ \\
\hline Avoid physical threat & 2 & $4.7 \%$ \\
\hline Don't know & 4 & $9.5 \%$ \\
\hline Total & $\mathbf{4 2}$ & $\mathbf{1 0 0 \%}$ \\
\hline
\end{tabular}

(b) Why response should not be given

\begin{tabular}{|l|c|c|}
\hline Categories & Frequency & Percentage \\
\hline Should avoid them & 14 & $45.1 \%$ \\
\hline Response wont make any difference & 7 & $22.5 \%$ \\
\hline No response & 10 & $32.2 \%$ \\
\hline Total & $\mathbf{3 1}$ & $\mathbf{1 0 0 \%}$ \\
\hline
\end{tabular}

Majority of students think that the harasser should be responded they think if response is given that will discourage the harasser from doing further harassment. And those who said no response should be given said the best cure is that such people should always be avoided and some think that even if the harasser is responded in any way it won't make any difference.

Table No 4

Whether the Incidence of Harassment had been Discussed or not

\begin{tabular}{|l|c|c|}
\hline Categories & Frequency & Percentage \\
\hline Yes & 52 & $65 \%$ \\
\hline No & 21 & $26.2 \%$ \\
\hline No response & 7 & $8.75 \%$ \\
\hline Total & $\mathbf{8 0}$ & $\mathbf{1 0 0 \%}$ \\
\hline
\end{tabular}


(a) With whom it was discussed:

\begin{tabular}{|l|c|c|}
\hline Categories & Frequency & Percentage \\
\hline Mother & 21 & $40.3 \%$ \\
\hline Friends & 23 & $44.2 \%$ \\
\hline Other & 5 & $9.6 \%$ \\
\hline No response & 3 & $5.7 \%$ \\
\hline Total & $\mathbf{5 2}$ & $\mathbf{1 0 0 \%}$ \\
\hline
\end{tabular}

(b) Why it was not discussed

\begin{tabular}{|l|c|c|}
\hline Categories & Frequency & Percentage \\
\hline Just ignore & 8 & $38 \%$ \\
\hline No one reliable & 6 & $28.5 \%$ \\
\hline Taken as fun & 7 & $33.3 \%$ \\
\hline Total & $\mathbf{2 1}$ & $\mathbf{1 0 0 \%}$ \\
\hline
\end{tabular}

Most of the harassed students had discussed the incidence with their friends. Some girls have discussed it with their mothers and those who had not discussed had just ignored it, most of them had taken it as a fun and some found no one reliable enough to share such incidence.

\section{Who is to Believe the Victims Words?}

Most people said only their parents will believe them. Some believed their friends will take their words and some said no one would believe them. Some of the girls felt they better share it with their mother or siblings who can better understand them.

Table No 5

Reason of Harassment

\begin{tabular}{|l|c|c|}
\hline Categories & Frequency & Percentage \\
\hline Frustration & 31 & $38.7 \%$ \\
\hline Impact of media & 7 & $8.7 \%$ \\
\hline Lack of proper guidance/education & 6 & $7.5 \%$ \\
\hline Sexual Instinct & 9 & $11.2 \%$ \\
\hline Lack of religious education & 4 & $5 \%$ \\
\hline Male supremacy & 4 & $5 \%$ \\
\hline Confidence building & 3 & $3.7 \%$ \\
\hline Don't know & 7 & $8.7 \%$ \\
\hline Others & 9 & $11.2 \%$ \\
\hline Total & $\mathbf{8 0}$ & $\mathbf{1 0 0 \%}$ \\
\hline
\end{tabular}


On being asked what could possibly be the reason of harassment, the majority referred to personal grudge and frustration. They said it isn't any reason from the outside world but from his inner world; there might exist aggression and frustration as a result of his/her disapproval or disappointments in his/her life. Thus they gave a psychological reason for harassment. Some said it might be sexual instincts in a person as the victim is usually one from the opposite sex and in order to express ones sexual nature one harasses a person from the opposite sex. Some thought it is because of the media which presents such incidents frequently and the viewer adopts and acquires such behavior. Some girls mentioned that boys harass girls to show their superiority over them and some said it is because of lack of education/proper guidance and because of ignorance among common people. A few number of students also mentioned that the lack of religious education leads a person to do such act and one guy feels that harassment is important for confidence building specially while talking to girls.

\section{Number of Subjects who have Harassed}

$51 \%$ students declared that they have harassed other people, most of them said they have harassed by verbal means, $12 \%$ had harassed through phone calls. The majority of those who had not harassed anyone gave the reason that they don't like doing such acts and some were scared of their families and that they might be reported. 2 boys told that they had never got a chance and are still looking for a chance to harass others.

Table No 6

Reason for Harassing

\begin{tabular}{|l|c|c|}
\hline Categories & Frequency & Percentage \\
\hline To have fun & 26 & $32.5 \%$ \\
\hline Jealousy & 8 & $10 \%$ \\
\hline Frustration & 11 & $13.7 \%$ \\
\hline No particular reason & 13 & $16.2 \%$ \\
\hline No response & 22 & $27.5 \%$ \\
\hline Total & $\mathbf{8 0}$ & $\mathbf{1 0 0} \%$ \\
\hline
\end{tabular}

The majority did harass to enjoy and have fun and some to overcome their inner frustration. Some found no particular reason of harassment and a few number of students harassed because of jealousy and complex.

\section{Whether been Punished or not}

$21.2 \%$ of the harassers were punished and $76.2 \%$ were not. 
Table No 7

Way of Punishment

\begin{tabular}{|l|c|c|}
\hline Categories & Frequency & Percentage \\
\hline Verbally & 2 & $11.7 \%$ \\
\hline Physically & 4 & $23.5 \%$ \\
\hline Charged/ fine & 1 & $5.8 \%$ \\
\hline Others & 3 & $17.6 \%$ \\
\hline No response & 7 & $41.1 \%$ \\
\hline Total & $\mathbf{1 7}$ & $\mathbf{1 0 0 \%}$ \\
\hline
\end{tabular}

The majority of the harassers didn't disclose how they were punished whereas some were given physical punishment and some have verbal notifications. One of the harasser reported of been beaten with a leather belt.

\section{(a) Why not Punished?}

Majority of those who were not punished think that it is not an issue of being punished, for they only took it for fun. Some said it depends on the person who was harassed that the harasser is punished or not. Some remained unnoticed and 12 person didn't know why they were not punished.

It was told by most of the harassers that their victims showed anger but gave no verbal reply. Again the second largest among them are those who just ignored and kept silence. Some were embarrassed and some were shocked as well.

\section{If any Friend been Harassed}

A large majority confessed that they had seen incidence of harassment with their friends. Again most of the cases were by verbal means and some also told the incidents of touching.

\section{Table No 8}

University Environment

\begin{tabular}{|l|c|c|}
\hline Categories & Frequency & Percentage \\
\hline Peaceful & 10 & $12.5 \%$ \\
\hline Irritating & 11 & $13.7 \%$ \\
\hline Enjoyable & 43 & $53.7 \%$ \\
\hline Others & 7 & $8.7 \%$ \\
\hline No response & 11 & $13.7 \%$ \\
\hline Total & $\mathbf{8 0}$ & $\mathbf{1 0 0} \%$ \\
\hline
\end{tabular}


For most students the environment at the university is enjoyable but for some it is irritating. The environment of the university is very important to be mentioned as it is the working zone for students. Irritating or annoying environment depicts that the working environment is uncomfortable for some of the students and it directly affect their studies.

\section{Table No 9}

If ever Abusive Language had been Used by the Depts. Staff

\begin{tabular}{|l|c|c|}
\hline Categories & Frequency & Percentage \\
\hline Yes & 44 & $55 \%$ \\
\hline No & 23 & $28.7 \%$ \\
\hline No response & 13 & $16.2 \%$ \\
\hline Total & $\mathbf{8 0}$ & $\mathbf{1 0 0 \%}$ \\
\hline
\end{tabular}

Majority of the students told that abusive language is used in depts., usually by the grade one staff.

Table No 10

If ever Heard Comments about Makeup, Dressing or Physique

\begin{tabular}{|l|c|c|}
\hline Categories & Frequency & Percentage \\
\hline Yes & 61 & $76.2 \%$ \\
\hline No & 15 & $18.7 \%$ \\
\hline No response & 4 & $5 \%$ \\
\hline Total & $\mathbf{8 0}$ & $\mathbf{1 0 0 \%}$ \\
\hline
\end{tabular}

Table No 11

What the Comments were about

\begin{tabular}{|l|c|c|}
\hline Categories & Frequency & Percentage \\
\hline Dressing & 21 & $26.2 \%$ \\
\hline Makeup & 11 & $13.7 \%$ \\
\hline Physique & 25 & $31.2 \%$ \\
\hline Other & 7 & $8.7 \%$ \\
\hline No response & 16 & $20 \%$ \\
\hline Total & $\mathbf{8 0}$ & $\mathbf{1 0 0 \%}$ \\
\hline
\end{tabular}

About $76.2 \%$ students hear comments about their dressing, makeup etc. Most comments are given on physique $(31.2 \%)$ and dressing (26.2\%). Some girls complained of hearing comments on their makeup. One said that she hears guys giving comments like 'miss. Universe'. One master's boy said he once heard a girl commenting his hair 'balon mein bomb phatah!' 


\section{Different Attitudes at University}

$25 \%$ students complained of hearing sexual talks and noticed sexual advances within the university premises. $22 \%$ heard dirty jokes that were offensive and $18 \%$ saw touching incidences.

Table No 12

Knowledge about the Law of Harassment

\begin{tabular}{|l|c|c|}
\hline Categories & Frequency & Percentage \\
\hline Yes & 18 & $22.5 \%$ \\
\hline No & 61 & $76.25 \%$ \\
\hline No response & 1 & $1.25 \%$ \\
\hline Total & $\mathbf{8 0}$ & $\mathbf{1 0 0 \%}$ \\
\hline
\end{tabular}

(a) What they know about the law

\begin{tabular}{|l|c|c|}
\hline Categories & Frequency & Percentage \\
\hline Unaware of article & 13 & $72.2 \%$ \\
\hline Gives punishment & 2 & $11.1 \%$ \\
\hline Others & 2 & $11.15 \%$ \\
\hline No response & 1 & $5.5 \%$ \\
\hline Total & $\mathbf{1 8}$ & $\mathbf{1 0 0 \%}$ \\
\hline
\end{tabular}

(a) why they are unaware of the law:

\begin{tabular}{|l|c|c|}
\hline Categories & Frequency & Percentage \\
\hline Law is not common & 6 & $9.8 \%$ \\
\hline Lack of interest & 17 & $27.8 \%$ \\
\hline Never bothered to know & 16 & $26.2 \%$ \\
\hline Insufficient media information & 13 & $21.3 \%$ \\
\hline Don't know & 3 & $4.9 \%$ \\
\hline No response & 6 & $9.8 \%$ \\
\hline Total & $\mathbf{6 1}$ & $\mathbf{1 0 0 \%}$ \\
\hline
\end{tabular}

No one among the subjects knew exactly about the law of harassment (72.2\%). Most of them said that they had heard there is a law regarding harassment $(22.5 \%)$ but they didn't know what the law says. Though some said it is about giving punishment to the harasser $(11.1 \%)$. Majority of them showed lack of interest in knowing what the law was about (27.8\%). 26.2\% again never bothered to know. A large number of students said it is because of lack of proper media information that they do not know about it $(21.3 \%)$. 


\section{Whether Such Incidents will be Reported in Future or not}

After being aware of the law most of the students agreed to report an incidence of harassment in future $(57.5 \%)$ but some still refused to report it $(36.2 \%)$. The reason might be because as they had mentioned before they though there is law but is rarely implemented or might be because they feel it isn't a big issue to be reported.

\section{Suggestions}

Most of the students said people are unaware of the law surely because it had never been implemented and the victims too refrain to report it that's why, therefore the law should be implemented at the first place (51\%). Second largest group said there should be awareness provoking workshops and seminars so that people be aware of it $(22.5 \%)$. Some people said that the victim should feel strong enough to take stand against the harasser so that the incidence can be reported $(2.5 \%)$.

\section{Discussion}

Likewise in other educational institutions sexual harassment level is thought provoking in Karachi University. Though some of the students harass others to have fun but it might cause some serious problem to the harasser. Harassment leads to low self esteem, thus it is not just a physical or verbal threat but emotional and psychological as well. Male students harass to show their supremacy, on the other hand girls face touching in buses. Those men try to show their dominant sexual nature as the theory of patriarchy describes them.

\section{Conclusions}

Harassment level at the university is higher comparatively to other places. Most of the students unveiled that they were harassed in university $(37 \%)$.

$72 \%$ complained of seeing a harassment incident at the university campus. Students also reported of sexual talks and abusive language used by the dept. staff. They are unaware of the law regarding sexual harassment.

\section{Recommendations}

- The university should appoint a committee of three teachers specially women teachers to inquire into serious charges of harassment.

- If this committee records someone findings of guilt, the person responsible should be suspended in anticipation of disciplinary proceedings.

- Workshops should be held for awareness rising about laws of harassment. 


\section{End Notes}

1. Hall, R.M., \& Sandler, B.R. (1986). The campus climate revisited: Chilly for Women Faculty, Administrators, and Graduate Students, Washington. DC: Project on the Status and Education of Women, Association of American Colleges.

2. ILO survey of industrialized countries report, 1992.

3. http://www.un.org/womenwatch/daw/cedaw/committ.htm retrieved on 15th Dec, 2012

4. Workplace Sexual Harassment, http:/www.aware.org.sg/ati/wsh-site/9-share/ , retrieved on Jan., 3, 2013.

5. The Gazette of Pakistan (2010). The Protection Against Harassment of Women at the Workplace act 2010, Islamabad. Senate Secretariat.

6. Dzeich, Billie Wright and Linda Weiner (1990). The Lecherous Professor: Sexual Harassment on Campus, University of Illinois Press.

7. Veraldi, Lorna. (1995). Academic Freedom and Sexual Harassment. Education Digest, 61(1),p.39.

8. The Minnesota Daily (March 5, 2007). Sexual Harassment on Study Abroad, Minnesota, The Minnesota Daily.

9. Cortina, Lilia M. (et.al) (1997). Sexual Harassment and Assault: Chilling the Climate for Women in Academia, Urbana, University of Illinois.

10. Lerner, Gerda (1986). The Creation of Patriarchy, Oxford, Oxford University Press.

11. Sexual Harassment-biology or sociology, http://www.mightystudents.com/essay/ Sexual.harassment.essay.71128, retrieved on Jan., 10,2013

12. Bada, Mayonnie (Feb., 23-March 1, 2003). Culture and social Structures, Paper presented at $44^{\text {th }}$ Annual International Studies Association Convention.

13. Bagshaw, Dale Margaret (2004). Verbal Abuse and Adolescent Identities: Marketing the Boundaries of Gender, The University of Melbourne. 
14. Deepali Chandhoke (1996). Impact of Sexual Harassment on Women, http://www.legalserviceindia.com/helpline/help6.htm, retrieved on Dec., 20, 2013.

15. Teicher, Stacy A. (Sept., 22, 1999). Boys vs. Girls: name-calling's nasty turn, Washington, The Christian Science Monitor.

16. Lee, Valerie E. (1996). The Culture of Sexual Harassment in Secondary Schools in American Educational Research Journal, Vol.33, No,2, pp.383-417.

17. http://womensissues.about.com/cs/governornews/a/sexharassstats.htm, retrieved on Dec., 10, 2012.

Asma Manzoor is Co-operative Teacher in the Centre of Excellence for Women's Studies, University of Karachi.

Dr. Muhammad Nadeemullah is Assistant Professor in the Department of Social Work, University of Karachi.

Syed Faisal Hashmi is Research Officer in the Centre of Excellence for Women's Studies, University of Karachi. 